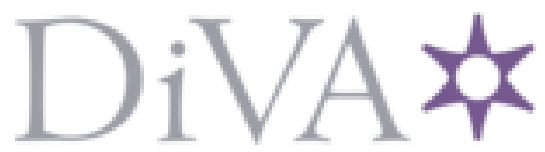

http://www.diva-portal.org

\title{
Postprint
}

This is the accepted version of a paper presented at PMAPS 20162016 International Conference on Probabilistic Methods Applied to Power Systems Oct. 16-20, 2016 Beijing, China.

Citation for the original published paper:

Westerlund, P., Hilber, P., Lindquist, T. (2016)

Prediction of current in a substation in order to schedule thermography.

In: 2016 INTERNATIONAL CONFERENCE ON PROBABILISTIC METHODS APPLIED TO POWER SYSTEMS (PMAPS) IEEE

https://doi.org/10.1109/PMAPS.2016.7764223

N.B. When citing this work, cite the original published paper.

Permanent link to this version:

http://urn.kb.se/resolve?urn=urn:nbn:se:kth:diva-193911 


\section{Prediction of current in a substation in order to schedule thermography}

\author{
Per Westerlund, Patrik Hilber \\ Department of Electromagnetic Engineering \\ School of Electrical Engineering \\ KTH Royal Institute of Technology \\ Osquldas väg 10 \\ SE-100 44 Stockholm \\ Sweden \\ email: per.westerlund@ee.kth.se
}

\author{
Tommie Lindquist \\ Svenska kraftnät \\ Swedish National Grid \\ Box 1200 \\ SE-172 24 Sundbyberg \\ Sweden
}

\begin{abstract}
It is important to predict the current in a line in the electrical grid for example when planning thermography or handling dynamic rating. This paper takes data from a Swedish substation from 10 years and applies analysis of variance (ANOVA) to construct a linear model. The factors are the time of the day, the day of the week and the week number. About two thirds of the variance in the data can be explained by the model, but the means are too low to attain a current of at least one third of the current for which the equipment is rated. Thus the model is not good enough to plan thermography for the studied bay in the substation. However the model is able to predict the current and can also be used to predict power flows in the electric network.
\end{abstract}

Keywords-Analysis of variance, infrared sensors, prediction algorithms, substations, thermography.

\section{INT'RODUC'TION}

The electric grid consists of overhead lines and cables connected at substations. The current in a line or cable varies throughout the day and during the whole year. It is interesting to predict the current, for example, if thermography should be done to equipment connected to that line, as thermography is more accurate at high currents. Also dynamic rating is based on predicting the current of the line.

\section{DATA}

The current in a line between two substations in the Swedish transmission grid has been recorded for a period of more than 10 years. The current is given in amperes and it is sampled once every hour. The histogram of the current is shown in Fig. 1. As thermography depends only on the magnitude of the current and not on the sign, Fig. 2 shows the histogram of the absolute value of the current.

\section{ANALYSIS OF VARIANCE}

The method used for analysis is the so called analysis of variance (ANOVA), which tries to divide the data into groups with different means but the same variance. In order to assess if the division into groups is relevant, the square root of variance within the groups is compared to the difference of

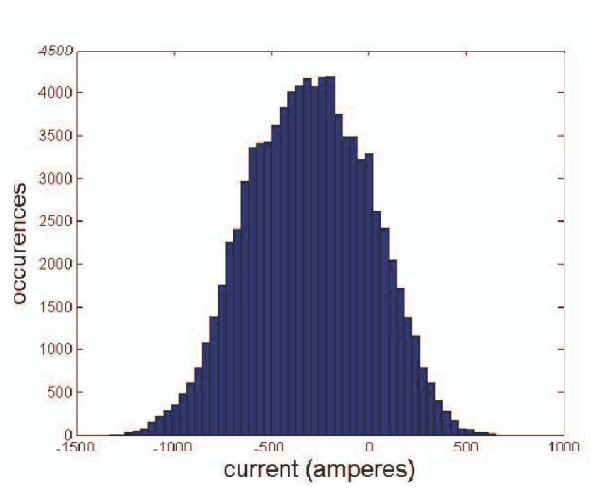

Fig. 1. Histogram of the current in the studied substation.

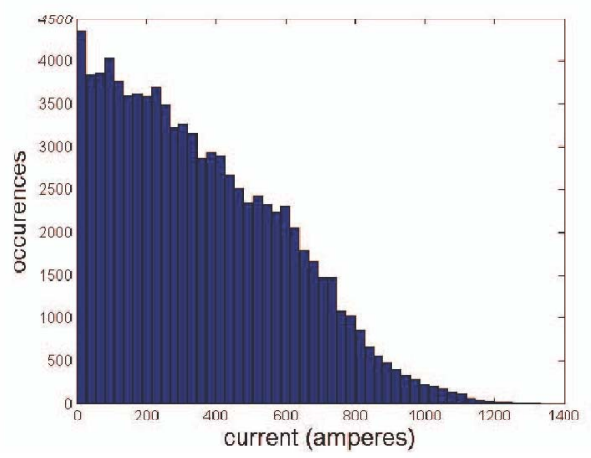

Fig. 2. Histogram of the absolute value of the current in the studied substation.

means. This explanation of the method of analysis of variance is based on [1, Sec. 9.2.1], [2, Sec 8.1-8.3] and [3].

\section{ONE FACTOR}

\section{A. Theoretical overview}

As a first case, there is just one factor with a levels, so the data are structured as in Table I. The sample means are notated with a bar above and a dot instead of the index or indices for which the mean is taken. 
TABLE I

Structure OF THE DATA WiTH ONE FACTOR.

\begin{tabular}{c|c|c|c|c} 
Population & $\begin{array}{c}\text { Sample } \\
\text { size }\end{array}$ & Observations & $\begin{array}{c}\text { Sample } \\
\text { means }\end{array}$ & $\begin{array}{c}\text { Population } \\
\text { means }\end{array}$ \\
\hline 1 & $n_{1}$ & $X_{11}, \ldots, X_{1 n_{1}}$ & $\bar{X}_{1}$ & $\mu_{1}$ \\
$\vdots$ & $\vdots$ & $\vdots$ & $\vdots$ & $\vdots$ \\
$a$ & $n_{a}$ & $X_{1}, \ldots, X_{a n_{a}}$ & $\bar{X}_{a}$ & $\mu_{a}$ \\
\hline Totally: & $n$ & & $\bar{X} .$. & $\mu$
\end{tabular}

The model is thus described as:

$$
\begin{aligned}
X_{i j} & =\mu_{i}+\epsilon_{i j}, \\
\text { where } i & =1, \ldots, a \text { and } \\
j & =1, \ldots, n_{i},
\end{aligned}
$$

where $\mu_{i}$ are the parameters to be estimated and $\epsilon_{i j}$ are the errors or nonexplained terms, which are supposed to be distributed as $N\left(0, \sigma^{2}\right)$ and to be independent of each other.

The maximum likelihood estimates (MLE) are:

$$
\begin{aligned}
\hat{\mu}_{i} & =\bar{X}_{i} \text { for } i=1, \ldots, a \text { and } \\
\hat{\sigma}^{2} & =\frac{1}{n} \sum_{i=1}^{a} \sum_{j=1}^{n_{a}}\left(X_{i j}-\bar{X}_{i}\right)^{2} .
\end{aligned}
$$

It is convenient to make a variable change in order to have a mean for all groups, $\mu$ :

$$
\mu_{i}=\mu+\alpha_{i} .
$$

There are still only $a$ independent parameters as $\sum_{i=1}^{a} \alpha_{i}=$ 0 . The new maximum-likelihood estimates are:

$$
\begin{aligned}
\hat{\mu} & =\bar{X}_{. . \text {and }} \\
\hat{\alpha}_{i} & =\bar{X}_{i .}-\bar{X}_{. .} \text {for } i=1, \ldots, a .
\end{aligned}
$$

\section{B. Calculations}

The total sum of squares (SS(Tot)) can be divided as in Table II. The third term in the sum on the second row cancels as the inner sum over $j$ equals 0 . Table III shows how the calculations are carried out. Its last column contains the expected value of the mean sums of squares.

Then the null hypothesis $H_{0}$ is $\theta_{i}=0$ for all $i$ from 0 to $a$. Hence the expected value of the mean sum of squares (MS) will be the same for both between groups and within groups.

If $H_{0}$ is true then MS(A) will be distributed as $\chi^{2}(a-1)$ and MS(Err) as $\chi^{2}(n-a)$ according to Cochran's theorem [1, p 375-377]. Then MS(A)/MS(Err) will be distributed as $F(a-$ $1, n-a)$ and an $\alpha$ level test for rejecting $H_{0}$ will be:

$$
\operatorname{MS}(\mathrm{A}) / \mathrm{MS}(\mathrm{Err})>F_{\alpha}(a-1, n-a),
$$

where the value $F_{\alpha}(a-1, n-a)$ can be found in tables such as [1, Table IVa and IVb]. If there are just two groups, $a$ equals 2 and the $F$ distribution will have parameters 1 and $n-2$, which will result in the $t$ distribution with parameter $n-2$. The test is then the familiar $t$ test.

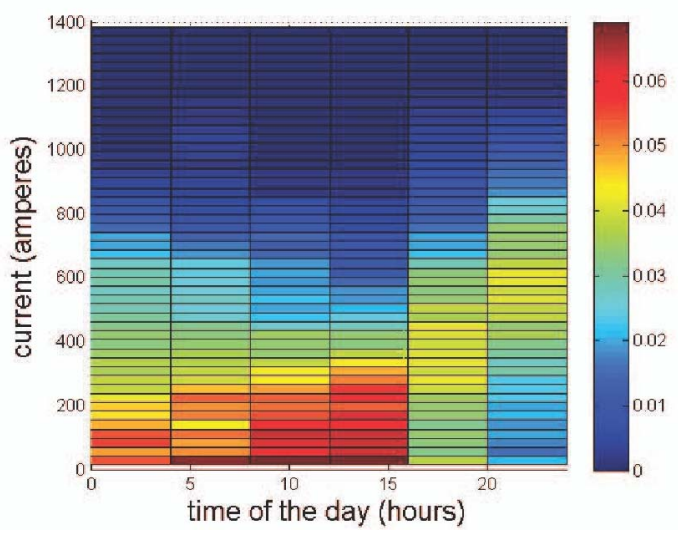

Fig. 3. Histogram for the current distributed in periods of 4 hours along the day.

\section{Results}

The time of the day is taken as the first factor. For a period of 4 hours the current is distributed according to the coloured and normalized histograms in Fig. 3. Table IV shows the output of anova 1 in Matlab, corresponding to the calculations in Table III. The estimated means appear in Table V.

TABLE IV

MATLAB OUTPUT FOR A PERIOD OF 4 HOURS.

\begin{tabular}{l|r|r|r|r|r} 
Source & SS & df & MS & F & Prob $>F$ \\
\hline Columns & $6.24597 \mathrm{e}+08$ & 5 & 124919366.4 & 2297.28 & 0 \\
Error & $4.79312 \mathrm{e}+09$ & 88146 & 54377.1 & & \\
Total & $5.41772 \mathrm{e}+09$ & 88151 & & &
\end{tabular}

TABLE V

MEANS FOR THE DIFFERENT PERIODS OF 4 HOURS,

\begin{tabular}{r|r|r}
$\begin{array}{r}\text { Period of } \\
\text { the day }\end{array}$ & $\begin{array}{r}\text { Estimated } \\
\text { mean }\end{array}$ & $\begin{array}{r}\text { Variance of } \\
\text { the estimation }\end{array}$ \\
\hline $0-4$ & 336.6171 & 1.9238 \\
$4-8$ & 325.8298 & 1.9238 \\
$8-12$ & 287.4980 & 1.9238 \\
$12-16$ & 265.3090 & 1.9238 \\
$16-20$ & 404.8330 & 1.9238 \\
$20-24$ & 517.0123 & 1.9238
\end{tabular}

Fig. 4 shows the distribution of the current for all the 24 hours in a day. Table VI presents the results for the possible periods in which a 24-hour day can be divided, which are the divisors of 24 .

\section{Discussion}

The degree of explanation $R^{2}$ increases in general when the length of the period decreases. Fig. 3 and 4 show that the variation between hours cannot be captured by periods of 4 hours. However $R^{2}$ does not increase when going from three periods of 8 hours to four periods of 6 hours, because the later division is not a finer division of the 24 hours than the first 
TABLE II

DIVISION OF THE SUM OF SQUARES FOR THE ONE-FACTOR EXPERIMENT.

$$
\begin{aligned}
& \mathrm{SS}(\mathrm{Tot})=\sum_{i=1}^{a} \sum_{j=1}^{n_{i}}\left(X_{i j}-\bar{X}_{.}\right)^{2}=\sum_{i=1}^{a} \sum_{j=1}^{n_{i}}\left(X_{i j}-\bar{X}_{i} \cdot+\bar{X}_{i} \cdot-\bar{X}_{.} .\right)^{2}= \\
& =\sum_{i=1}^{a} \sum_{j=1}^{n_{i}}\left(\left(X_{i j}-\bar{X}_{i} \cdot\right)^{2}+\left(\bar{X}_{i} .-\bar{X}_{. .}\right)^{2}+2\left(X_{i j}-\bar{X}_{i} .\right)\left(\bar{X}_{i} \cdot-\bar{X}_{. .}\right)\right)= \\
& =\sum_{i=1}^{a} \sum_{j=1}^{n_{i}}\left(\left(X_{i j}-\bar{X}_{i} \cdot\right)^{2}+\left(\bar{X}_{i} \cdot-\bar{X}_{.}\right)^{2}\right)=\sum_{i=1}^{a} \sum_{j=1}^{n_{i}}\left(X_{i j}-\bar{X}_{i}\right)^{2}+\sum_{i=1}^{a} n_{i}\left(\bar{X}_{i}-\bar{X}_{. .}\right)^{2}=\operatorname{SS}(\mathrm{A})+\operatorname{SS}(\text { Err })
\end{aligned}
$$

TABLE III

CAlculations For ONE FACTOR.

\begin{tabular}{c|c|c|c|c}
$\begin{array}{c}\text { Source of } \\
\text { variation }\end{array}$ & $\begin{array}{c}\text { Degrees of } \\
\text { freedom }\end{array}$ & $\begin{array}{c}\text { Sum of squares } \\
\text { (SS) }\end{array}$ & $\begin{array}{c}\text { Mean sum of } \\
\text { squares (MS) }\end{array}$ & $\begin{array}{c}\text { Expected value } \\
\text { of MS }\end{array}$ \\
\hline Between groups & $a-1$ & $\sum_{i=1}^{a} n_{i}\left(\bar{X}_{i}-\bar{X}_{.}\right)^{2}$ & $\frac{S S}{a-1}$ & $\sigma^{2}+\frac{1}{a-1} \sum_{i=1}^{a} n_{i} \alpha_{i}^{2}$ \\
Within groups & $n-a$ & $\sum_{i=1}^{a} \sum_{j=1}^{n_{i}}\left(X_{i j}-\bar{X}_{i} .\right)^{2}$ & $\hat{\sigma}^{2}$ & $\sigma^{2}$ \\
\hline Total & $n-1$ & $\sum_{i=1}^{a} \sum_{j=1}^{n_{i}}\left(X_{i j}-\bar{X}_{.}\right)^{2}$ & &
\end{tabular}

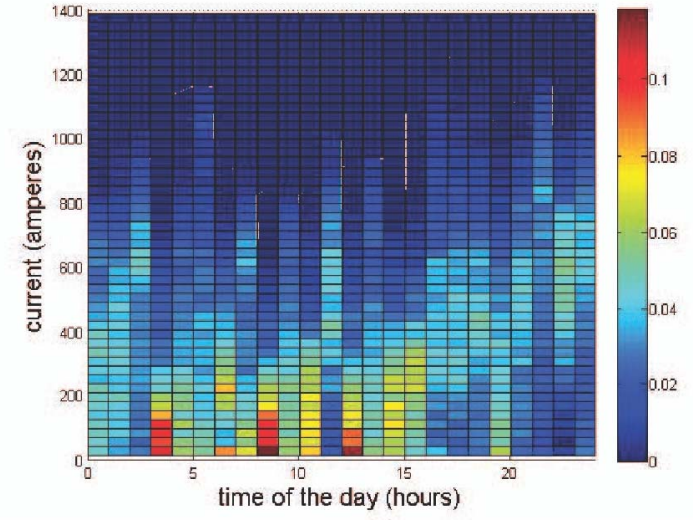

Fig. 4. Histogram for all the 24 hours of a day.

TABLE VI

$R^{2}$ AND $\sigma^{2}$ FOR THE DIFFERENT PERIODS OF 24 HOURS,

\begin{tabular}{r|r|r|r|r}
$\begin{array}{r}\text { Length of } \\
\text { the period (h) }\end{array}$ & $\begin{array}{r}\sigma^{2} \text { between } \\
\text { groups }\end{array}$ & $\begin{array}{r}\sigma^{2} \text { within } \\
\text { groups }\end{array}$ & Total $\sigma^{2}$ & $R^{2}$ \\
\hline 1 & $1.0506 \mathrm{e}+09$ & $4.3672 \mathrm{e}+09$ & $5.4177 \mathrm{e}+09$ & 0.1939 \\
2 & $0.6846 \mathrm{e}+09$ & $4.7331 \mathrm{e}+09$ & $5.4177 \mathrm{e}+09$ & 0.1264 \\
3 & $0.6598 \mathrm{e}+09$ & $4.7579 \mathrm{e}+09$ & $5.4177 \mathrm{e}+09$ & 0.1218 \\
4 & $0.6246 \mathrm{e}+09$ & $4.7931 \mathrm{e}+09$ & $5.4177 \mathrm{e}+09$ & 0.1153 \\
6 & $0.4092 \mathrm{e}+09$ & $5.0086 \mathrm{e}+09$ & $5.4177 \mathrm{e}+09$ & 0.0755 \\
8 & $0.5277 \mathrm{e}+09$ & $4.8900 \mathrm{e}+09$ & $5.4177 \mathrm{e}+09$ & 0.0974 \\
12 & $0.1378 \mathrm{e}+09$ & $5.2799 \mathrm{e}+09$ & $5.4177 \mathrm{e}+09$ & 0.0254 \\
24 & 0 & $5.4177 \mathrm{e}+09$ & $5.4177 \mathrm{e}+09$ & 0
\end{tabular}

one. The divisions form a partial order [4, section 3.6], where a finer division has a larger $R^{2}$.

The Fourier analysis of the residuals is shown in Fig. 5. The residuals are the amounts that remain without explanation, i.e.

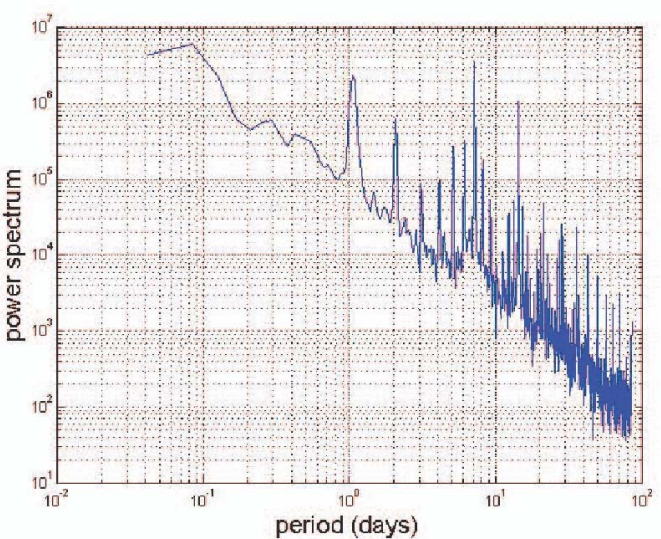

Fig. 5. Fourier analysis of residuals

the terms $\epsilon_{i j}$ in equation 1 . There are two peaks that surpass the others and they are at 7 and 14 days. Hence there is need to include the day of the week.

\section{TWO FACTORS AND INTERACTION}

The two factors are the time of the day and the day of the week. The new factor, the day of the week, is used in two ways: division into working days (Monday-Friday) and weekends (Saturday-Sunday) respectively every day is separate, i.e. seven different groups. The interaction can describe phenomena like a lower consumption of electricity during Friday afternoons if the industry tends to close earlier before the weekend. 


\section{A. Theoretical overview}

The model is described as with the notation in [3]:

$$
\begin{aligned}
X_{i j k} & =\mu+\alpha_{i}+\beta_{j}+(\alpha \beta)_{i j}+\epsilon_{i j k}, \\
\text { where } i & =1, \ldots, a \\
j & =1, \ldots, b \text { and } \\
k & =1, \ldots, n_{i j},
\end{aligned}
$$

where the indexed parameters (all but $\mu$ ) sum to 0 . The term $(\alpha \beta)_{i j}$ captures the interaction between factor $\mathrm{A}$ at level $i$ and factor $\mathrm{B}$ at level $j$. The maximum-likelihood estimates are in Table VII.

TABLE VII

MAXIMUM-LIKELIHOOD ESTIMATORS FOR THE TWO-FACTOR EXPERIMENT.

$$
\begin{aligned}
\hat{\mu}= & \bar{X}_{\ldots .} \\
\hat{\alpha}_{i}= & \bar{X}_{i . .} \text { for } i=1, \ldots, a, \\
\hat{\beta}_{i}= & \bar{X}_{\cdot j} \text { for } j=1, \ldots, b, \\
\widehat{(\alpha \beta)_{i j}}= & \bar{X}_{i j .}-\bar{X}_{i . .}-\bar{X}_{\cdot j .}+\bar{X}_{\ldots} \\
& \text { for } i=1, \ldots, a \text { and } j=1, \ldots, b \\
\hat{\sigma}^{2}= & \frac{1}{n} \sum_{i=1}^{a} \sum_{j=1}^{b} \sum_{k=1}^{n_{a b}}\left(X_{i j k}-\bar{X}_{i j} .\right)^{2}
\end{aligned}
$$

\section{B. Calculations}

The total sum of squares, SS(Tot), can be divided as in Table VIII. The calculations are shown in Table IX. The tests for the significance of factor A, factor B, and factor A together with $\mathrm{B}$ are then:

$$
\begin{aligned}
\mathrm{MS}(\mathrm{A}) / \mathrm{MS}(\mathrm{Err}) & >F_{\alpha}(a-1, m), \\
\mathrm{MS}(\mathrm{B}) / \mathrm{MS}(\mathrm{Err}) & >F_{\alpha}(b-1, m) \text { and } \\
\mathrm{MS}(\mathrm{AB}) / \mathrm{MS}(\mathrm{Err}) & >F_{\alpha}((a-1) \cdot(b-1), m),
\end{aligned}
$$

where $m=\sum_{i=1}^{a} \sum_{j=1}^{b}\left(n_{i j}-1\right)=n-1-(a-1)-(b-$ 1) $-(a-1) \cdot(b-1)=n-a b$ is the degree of freedom of the variation within groups.

\section{Results}

The calculations according to Table IX were done by the Matlab function anovan. Table $\mathrm{X}$ shows the output. The results for all the possible integer division of 24 hours and for the three tested are presented in Table XI.

\section{Discussion}

Table XI shows that there is no use in differentiating the days of the week. It suffices by dividing into weekends and the working days, Monday to Friday, as column 2 and 3 are better than column 1, except for the period of one hour.
TABLE $X$

MATLAB OUTPUT FOR A PERIOD OF 4 HOURS (X1) AND FOR A 2-5 DIVISION OF THE WEEK (X2).

\begin{tabular}{l|r|r|r|r|r} 
Source & Sum Sq. & d.f. & Mean Sq. & $\mathrm{F}$ & Prob $>\mathrm{F}$ \\
\hline $\mathrm{X} 1$ & $4.56788 \mathrm{e}+08$ & 5 & 91357685.6 & 1860.78 & 0 \\
$\mathrm{X} 2$ & $2.64256 \mathrm{e}+08$ & 1 & 264256027.7 & 5382.38 & 0 \\
$\mathrm{X} 1 * \mathrm{X} 2$ & $9.94387 \mathrm{e}+07$ & 5 & 19887743.9 & 405.07 & 0 \\
Error & $4.32737 \mathrm{e}+09$ & 88140 & $\mathbf{4 9 0 9 6 . 5}$ & & \\
Total & $5.41772 \mathrm{e}+09$ & 88151 & & &
\end{tabular}

TABLE XI

$R^{2}$ FOR THE DIFFERENT PERIODS OF 24 HOURS AND THE DIFFERENT DIVISION OF THE WEEK.

\begin{tabular}{r|r|r|r}
$\begin{array}{c}\text { Length of } \\
\text { the period (h) }\end{array}$ & $\begin{array}{r}R^{2} \text { for } \\
\text { the whole week }\end{array}$ & $\begin{array}{r}R^{2} \text { for } \\
\text { Mon-Fri/Sat-Sun }\end{array}$ & $\begin{array}{r}R^{2} \text { for } \\
\text { the } 7 \text { days }\end{array}$ \\
\hline 1 & 0.2430 & 0.2492 & 0.2524 \\
2 & 0.1402 & 0.2433 & 0.2463 \\
3 & 0.1387 & 0.2354 & 0.2384 \\
4 & 0.1270 & 0.2173 & 0.2202 \\
6 & 0.0673 & 0.2181 & 0.2210 \\
8 & 0.0945 & 0.1745 & 0.1771 \\
12 & 0.0091 & 0.0984 & 0.1006 \\
24 & 0 & 0.0550 & 0.0564
\end{tabular}

\section{THREE FACTORS AND INTERACTION}

The remaining factor is the week number. The weeks will be handled in groups of 1,4 or 13 , the factors of 52 . The factor 2 will not be used as it is close to 1 and 4 .

\section{A. Theoretical overview}

The model is described as with the notation in [3]:

$$
\begin{aligned}
X_{i j k l} & =\mu+\alpha_{i}+\beta_{j}+\gamma_{k}+(\alpha \beta)_{i j}+(\alpha \gamma)_{i k} \\
& +(\beta \gamma)_{j k}+(\alpha \beta \gamma)_{i j k}+\epsilon_{i j k l}, \\
\text { where } i & =1, \ldots, a, \\
j & =1, \ldots, b, \\
k & =1, \ldots, c \text { and } \\
l & =1, \ldots, n_{i j k},
\end{aligned}
$$

where the indexed parameters (all but $\mu$ ) sum to 0 .

\section{B. Calculations}

The maximum-likelihood estimates and the division of the sum of squares are similar to the case with two factors and interaction. Thus the calculation table is similar in structure but it has more rows.

\section{Results}

Table XII shows the output from the Matlab function anovan. Tables XIII-XV present the degree of explanation $R^{2}$ for several different divisions of the day, of the week and of the year. The complexity of the calculations increases, so only two years of data have been used. 
TABLE VIII

DIVISION OF THE SUM OF SQUARES FOR THE TWO-FACTOR EXPERIMENT.

$$
\begin{aligned}
& \mathrm{SS}(\mathrm{Tot})=\sum_{i=1}^{a} \sum_{j=1}^{b} \sum_{k=1}^{n_{i j}}\left(X_{i j k}-\bar{X} \ldots\right)^{2}=\sum_{i=1}^{a} \sum_{j=1}^{b} \sum_{k=1}^{n_{i j}}\left(X_{i j k}-\bar{X}_{i j}+\bar{X}_{i j .}-\bar{X}_{i . .}+\bar{X}_{i . .}-\bar{X}_{\cdot j .}+\bar{X}_{. j .}-\bar{X}_{\ldots}+\bar{X}_{\ldots}-\bar{X}_{\ldots}\right)^{2}= \\
& =\sum_{i=1}^{a} \sum_{j=1}^{b} \sum_{k=1}^{n_{i j}}\left(X_{i j k}-\bar{X}_{i j} .\right)^{2}+\sum_{i=1}^{a} \sum_{j=1}^{b} n_{i j}\left(\bar{X}_{i j}-\bar{X}_{i \cdot .}-\bar{X}_{\cdot j}+\bar{X}_{\ldots}\right)^{2}+ \\
& +\sum_{i=1}^{a} \sum_{j=1}^{b} n_{i j}\left(\bar{X}_{\cdot j}-\bar{X}_{\ldots}\right)^{2}+\sum_{i=1}^{a} \sum_{j=1}^{b} n_{i j}\left(\bar{X}_{i \cdot .}-\bar{X} \ldots\right)^{2}=\operatorname{SS}(\operatorname{Err})+\mathrm{SS}(\mathrm{AB})+\mathrm{SS}(\mathrm{B})+\operatorname{SS}(\mathrm{A})
\end{aligned}
$$

TABLE IX

CALCULATIONS FOR TWO FACTORS.

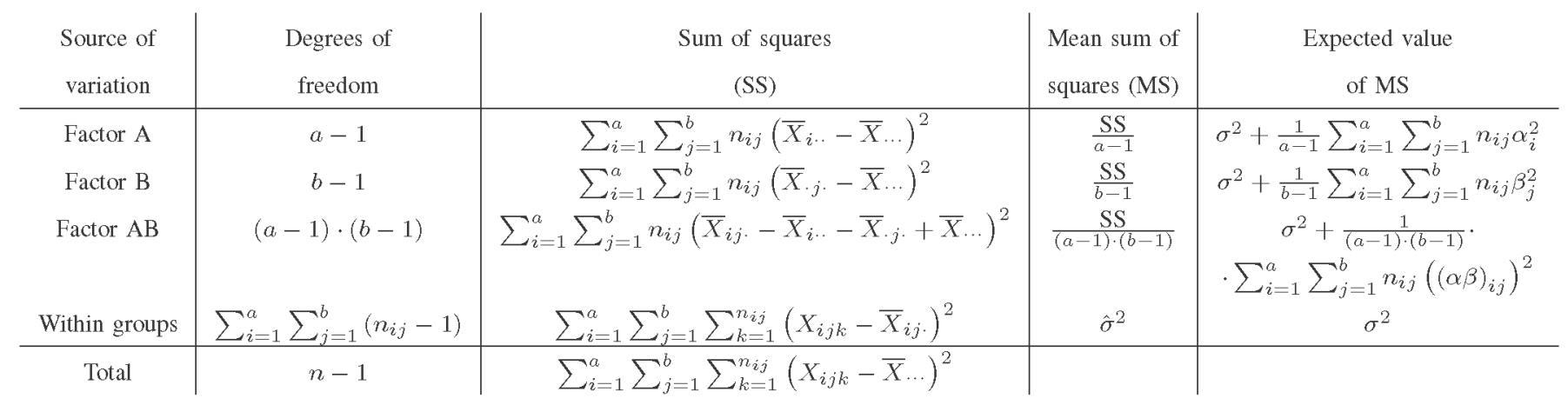

TABLE XII

MATLAB OUTPUT FOR A PERIOD OF 4 HOURS (X1), FOR A 2-5 DIVISION OF THE WEEK (X2) AND FOR PERIODS OF 4 WEEKS (X3).

\begin{tabular}{l|r|r|r|r|r} 
Source & Sum Sq. & d.f. & Mean Sq. & $\mathrm{F}$ & Prob $>\mathrm{F}$ \\
\hline $\mathrm{X} 1$ & 456766023 & 5 & 91353205 & 1862 & 0 \\
$\mathrm{X} 2$ & 264297569 & 1 & 264297569 & 5386 & 0 \\
$\mathrm{X} 3$ & 2369647 & 3 & 7898882 & 16.1 & 0 \\
$\mathrm{X} 1 * \mathrm{X} 2$ & 99441659 & 5 & 19888332 & 405 & 0 \\
$\mathrm{X} 1 * \mathrm{X} 3$ & 397080 & 15 & 26472 & 0.54 & 0.92 \\
$\mathrm{X} 2 * \mathrm{X} 3$ & 419226 & 3 & 139742 & 2.85 & 0.036 \\
$\mathrm{X} 1 * \mathrm{X} 2 * \mathrm{X} 3$ & 285108 & 15 & 19007 & 0.39 & 0.9828 \\
Error & 4323193772 & 88104 & 49069 & & \\
Total & 5417717081 & 88151 & & &
\end{tabular}

TABLE XIII

$R^{2}$ FOR THE DIFFERENT PERIODS OF 24 HOURS AND THE DIFFERENT PERIODS OF THE YEAR AND THE SEVEN DAYS OF THE WEEK.

\begin{tabular}{r|r|r|r|r} 
Period & \multicolumn{4}{|c}{$R^{2}$ for the year divided in periods of } \\
length (h) & 1 week & 4 weeks & 13 weeks & 52 weeks \\
\hline 1 & 0.7578 & 0.3828 & 0.3315 & 0.2368 \\
2 & 0.7419 & 0.3740 & 0.3240 & 0.3172 \\
3 & 0.7233 & 0.3630 & 0.3139 & 0.3074 \\
4 & 0.6929 & 0.3410 & 0.2932 & 0.2869 \\
6 & 0.6798 & 0.3400 & 0.2930 & 0.2868 \\
8 & 0.6271 & 0.2971 & 0.2513 & 0.2456 \\
12 & 0.4986 & 0.1909 & 0.1486 & 0.1436 \\
24 & 0.4151 & 0.1412 & 0.1033 & 0.0987
\end{tabular}

TABLE XIV

$R^{2}$ FOR THE DIFFERENT PERIODS OF 24 HOURS AND THE DIFFERENT PERIODS OF THE YEAR FOR THE DIVISION IN WORKING DAYS AND

WEEKEND.

\begin{tabular}{r|r|r|r|r} 
Period & \multicolumn{4}{|c}{$R^{2}$ for the year divided in periods of } \\
length (h) & 1 week & 4 weeks & 13 weeks & 52 weeks \\
\hline 1 & 0.6064 & 0.3294 & 0.2665 & 0.2648 \\
2 & 0.5965 & 0.3229 & 0.2605 & 0.2588 \\
3 & 0.5831 & 0.3142 & 0.2523 & 0.2507 \\
4 & 0.5599 & 0.2955 & 0.2343 & 0.2328 \\
6 & 0.5519 & 0.2959 & 0.2347 & 0.2332 \\
8 & 0.5078 & 0.2590 & 0.1988 & 0.1975 \\
12 & 0.4127 & 0.1734 & 0.1150 & 0.1141 \\
24 & 0.3497 & 0.1304 & 0.0746 & 0.0737
\end{tabular}

TABLE XV

$R^{2}$ FOR THE DIFFERENT PERIODS OF 24 HOURS AND THE DIFFERENT PERIODS OF THE YEAR FOR NO DIVISION OF THE DAYS OF THE WEEK,

\begin{tabular}{r|r|r|r|r} 
Period & \multicolumn{4}{|c}{$R^{2}$ for the year divided in periods of } \\
length (h) & 1 week & 4 weeks & 13 weeks & 52 weeks \\
\hline 1 & 0.5161 & 0.2226 & 0.1849 & 0.1819 \\
2 & 0.5057 & 0.2162 & 0.1790 & 0.1761 \\
3 & 0.4918 & 0.2071 & 0.1704 & 0.1676 \\
4 & 0.4712 & 0.1922 & 0.1560 & 0.1532 \\
6 & 0.4575 & 0.1883 & 0.1524 & 0.1496 \\
8 & 0.4234 & 0.1590 & 0.1238 & 0.1212 \\
12 & 0.3301 & 0.0799 & 0.0462 & 0.0439 \\
24 & 0.2572 & 0.0328 & 0.0022 & 0
\end{tabular}




\section{Discussion}

The degree of explication $R^{2}$ is relatively high, larger than 0.60 , for periods shorter than 8 hours and when the year is divided in weeks and the week at least in working days and weekend. With the available ten years $R^{2}$ should increase. Table XII shows that there is no interaction between the time of the day and the week number since the $F$ test gives too low values $(0.51$ and 0.44$)$.

\section{CURRENT WITH SIGN}

Taking the absolute value of the current is the same as not using all the information. In some cases as in predicting the power flow, it is also necessary to take into account the sign. Thus it is interesting to see how the analysis of variance works with the current with sign.

\section{A. Results}

Tables XVI-XVIII show the results using only two years of data. Table XIX is the output from Matlab with the most detailed division of the three factors.

TABLE XVI

$R^{2}$ FOR THE DIFFERENT PERIODS OF 24 HOURS AND THE DIFFERENT PERIODS OF THE YEAR FOR THE DIFFERENT DAYS OF THE WEEK HAVING IN MIND THE SIGN OF THE CURRENT.

\begin{tabular}{r|r|r|r|r} 
Period & \multicolumn{4}{|c}{$R^{2}$ for the year divided in periods of } \\
length (h) & 1 week & 4 weeks & 13 weeks & 52 weeks \\
\hline 1 & 0.7762 & 0.4258 & 0.3676 & 0.3631 \\
2 & 0.7633 & 0.4170 & 0.3594 & 0.3552 \\
3 & 0.7484 & 0.4067 & 0.3497 & 0.3456 \\
4 & 0.7184 & 0.3816 & 0.3253 & 0.3214 \\
6 & 0.7130 & 0.3866 & 0.3307 & 0.3268 \\
8 & 0.6630 & 0.3406 & 0.2855 & 0.2819 \\
12 & 0.5426 & 0.2331 & 0.1797 & 0.1767 \\
24 & 0.4620 & 0.1718 & 0.1206 & 0.1180
\end{tabular}

TABLE XVII

$R^{2}$ FOR THE DIFFERENT PERIODS OF 24 HOURS AND THE DIFFERENT PERIODS OF THE YEAR FOR THE DIVISION IN WORKING DAYS AND WEEKEND HAVING IN MIND THE SIGN OF THE CURRENT.

\begin{tabular}{r|r|r|r|r} 
Period & \multicolumn{4}{|c}{$R^{2}$ for the year divided in periods of } \\
length (h) & 1 week & 4 weeks & 13 weeks & 52 weeks \\
\hline 1 & 0.7136 & 0.4066 & 0.3585 & 0.3560 \\
2 & 0.7027 & 0.3984 & 0.3506 & 0.3482 \\
3 & 0.6895 & 0.3887 & 0.3412 & 0.3388 \\
4 & 0.6610 & 0.3640 & 0.3171 & 0.3148 \\
6 & 0.6570 & 0.3694 & 0.3224 & 0.3201 \\
8 & 0.6094 & 0.3243 & 0.2781 & 0.2760 \\
12 & 0.4944 & 0.2188 & 0.1735 & 0.1715 \\
24 & 0.4202 & 0.1595 & 0.1159 & 0.1141
\end{tabular}

\section{B. Discussion}

The increase in $R^{2}$ is not big, between 0.02 and 0.1 , which is reasonable since the current is mostly negative. The fact that the interaction between the time of the day (X1) and the week number (X3) became significant in Table XIX is due to that with shorter periods (one hour and one week respectively in this case) more factors are significant.
TABLE XVIII

$R^{2}$ FOR THE DIFFERENT PERIODS OF 24 HOURS AND THE DIFFERENT PERIODS OF THE YEAR WITHOUT DISTINCTION OF THE DIFFERENT DAYS OF THE WEEK BUT HAVING IN MIND THE SIGN OF THE CURRENT.

\begin{tabular}{r|r|r|r|r} 
Period & \multicolumn{4}{|c}{$R^{2}$ for the year divided in periods of } \\
length (h) & 1 week & 4 weeks & 13 weeks & 52 weeks \\
\hline 1 & 0.5382 & 0.2442 & 0.1985 & 0.1964 \\
2 & 0.5290 & 0.2373 & 0.1920 & 0.1899 \\
3 & 0.5173 & 0.2288 & 0.1837 & 0.1817 \\
4 & 0.4966 & 0.2115 & 0.1668 & 0.1649 \\
6 & 0.4889 & 0.2127 & 0.1679 & 0.1659 \\
8 & 0.4588 & 0.1846 & 0.1405 & 0.1386 \\
12 & 0.3680 & 0.1023 & 0.0589 & 0.0572 \\
24 & 0.2951 & 0.0435 & 0.0016 & 0
\end{tabular}

TABLE XIX

MATlab OUTPUT FOR A PERIOD OF 1 HOUR (X1), FOR A 7 DIVISION OF THE WEEK (X2) AND FOR PERIODS OF 1 WEEK (X3) HAVING IN MIND THE SIGN OF THE CURRENT.

\begin{tabular}{l|r|r|r|r|r} 
Source & Sum Sq. & d.f. & Mean Sq. & $\mathrm{F}$ & Prob $>\mathrm{F}$ \\
\hline $\mathrm{X} 1$ & $2.49441 \mathrm{e}+08$ & 7 & 35634470 & 1501 & 0 \\
$\mathrm{X} 2$ & $1.6204 \mathrm{e}+08$ & 6 & 27006629 & 1138 & 0 \\
$\mathrm{X} 3$ & $4.0527 \mathrm{e}+08$ & 51 & 7946476 & 335 & 0 \\
$\mathrm{X} 1 * \mathrm{X} 2$ & $6.31317 \mathrm{e}+07$ & 42 & 1503135 & 63.3 & 0 \\
$\mathrm{X} 1 * \mathrm{X} 3$ & $5.568 \mathrm{e}+07$ & 357 & 155966 & 6.57 & 0 \\
$\mathrm{X} 2 * \mathrm{X} 3$ & $6.71162 \mathrm{e}+07$ & 306 & 219334 & 9.24 & 0 \\
$\mathrm{X} 1 * \mathrm{X} 2 * \mathrm{X} 3$ & $2.49654 \mathrm{e}+07$ & 2142 & 11655 & 0.49 & 1 \\
Error & $3.45549 \mathrm{e}+08$ & 14560 & 23733 & & \\
Total & $1.37319 \mathrm{e}+09$ & 17471 & & &
\end{tabular}

\section{DISCUSSION AND CONCLUSION}

\section{A. Scheduling of thermography}

We can start by setting a level which the current should achieve in order to have an accurate thermography, $I_{0}$. Then the probability of attaining this level is:

$$
P\left\{|I| \geq I_{0}\right\}=1-\Phi\left(\frac{I_{0}-\mu}{\sigma}\right),
$$

where $\mu$ and $\sigma^{2}$ are the mean and the variance of the model. At a voltage of $400 \mathrm{kV} I_{0}$ can be set to $1000 \mathrm{~A}$, which is one third of the rated current for some disconnectors and circuit breakers. The estimated mean current is somewhere between $270 \mathrm{~A}$ and $570 \mathrm{~A}$ in Table V. Further calculations with more groups for every of the three factors will only reduce the variance. The means should be in that range.

If we assume that $R^{2}$ attains 0.70 with a model with more groups for the three factors, $\mathrm{SS}$ (Err) would be $4.9 \cdot 10^{9}$ and MS(Err) $4.3 \cdot 10^{4}$. The unit for both is ampere squared. Then the standard deviation is about 210 amperes and the one-sided $30 \%$ confidence interval will start at the mean plus 110 amperes. Thus the mean should be at least 890 A for a probability of $30 \%$ to get enough current for the thermography. The conclusion is than that the current is not enough big for an accurate thermography.

\section{B. Discussion}

The purpose is to test if the current in a line to a substation in the transmission grid can be predicted by a simple model taking into account only the date and time. 
The degree of explanation, $R^{2}$, is defined as the ratio of the remaining variation within the groups to the total variation and it reaches a level of between 0.6 and 0.7 if three variables are considered: the time of the day, the day of the week and the week number with interaction between them. The period of the year should be one week, the working days and the weekend should be counted apart and the length of the periods in which the day is divided should be less than 8 hours. That level is fairly high, as its limit is 1 . It would be interesting to try some other variable in order to explain more of the variation of the current.

Only one substation has been studied so far. It is situated in the route from the hydro power in northern Sweden to the consumption in southern Sweden, with some rivers close. It would be interesting to study substations situated close to production (both hydro power and nuclear power) as well as substations close to consumption (both industry and big cities).

\section{Conclusion}

The variation of the current in a line to a substation in the transmission grid can be predicted by using date and time in an analysis of variance. This paper takes data from a line to a Swedish substation from period of 10 years and applies analysis of variance to construct a linear model. The factors are the time of the day, the day of the week and week number with possible interactions. About two thirds of the variance in the data can be explained by the model, if the periods of the day, the week and the year are short enough. The problem is that the means of the current in the line are too low. Thus the model is not enough to plan thermography in this case. Still the model is suitable for prediction of the current for other purposes. Other lines in different position in the electric grid should be checked.

\section{ACKNOWLEDGMENT}

The research is funded by SweGRIDS, Swedish Centre for Smart Grids and Energy Storage, swegrids.se.

\section{REFERENCES}

[1] B. W. Lindgren, Statistical theory, 2nd ed. New York: Macmillan, 1968.

[2] R. V. Hogg and E. A. Tanis, Probability and statistical inference, 4th ed. New York: Macmillan, 1993.

[3] R. Sundberg, "Lineära stokastiska modeller," Stockholm University, Department of Mathematics, 2010.

[4] D. F. Stanat and D. F. McAllister, Discrete mathematics in computer science. Englewood Cliffs: Prentice-Hall, 1977. 